EXTENDED REPORT

\title{
Pregnancy in patients with rheumatic disease: anti- inflammatory cytokines increase in pregnancy and decrease post partum
}

\author{
M Østensen, F Förger, J L Nelson, A Schuhmacher, G Hebisch, P M Villiger
}

See end of article for authors' affiliations

Correspondence to:

Professor M Østensen, Department of Rheumatology and Clinical Immunology and Allergy, University Hospital, $\mathrm{CH}$ 3010 Bern, Switzerland; monika.oestensen@ insel.ch

Accepted

1 November 2004

Published Online First

11 November 2004

Objective: To investigate changes in the levels of circulating cytokines with a focus on the Th1/Th2 balance during and after pregnancy in patients with rheumatoid arthritis (RA), juvenile idiopathic arthritis (JIA), and ankylosing spondylitis (AS).

Methods: Plasma and serum samples of 34 pregnant patients, 19 with RA, 6 with JIA, and 9 with AS, and of 30 healthy pregnant women, 20 non-pregnant patients, and 10 non-pregnant healthy women were analysed for levels of interferon $\gamma$ (IFN $\gamma$ ), interleukin (IL) 1 $\beta$, IL10, IL1 receptor antagonist (ILIRa), soluble tumour necrosis factor receptor (sTNFR), and soluble CD30 (sCD30) by ELISA. Clinical assessment and blood sampling in pregnant women was done once in each trimester and 6, 12, and 24 weeks post partum. Disease activity in the patients was evaluated by validated clinical instruments and correlated with circulating levels of cytokines.

Results: Low levels of IL10 were found sporadically, whereas IFN $\gamma$ and IL1 $\beta$ were below detection level in the samples tested. Significantly higher concentrations of sTNFR and ILIRa were measured in pregnant than in non-pregnant subjects. An increase of IL1Ra from the second to the third trimester correlated with improvement of disease activity in patients with RA and AS. Compared with non-pregnant patients and the other pregnant women, patients with RA showed markedly raised levels of sCD30 during pregnancy.

Conclusions: IFN $\gamma$ and IL10, markers of a Th1 and Th2 response, respectively, were either low or undetectable in the cohorts analysed. The increase of cytokine inhibitors IL1 Ra and sTNFR was related to pregnancy and was independent of an underlying disease. These anti-inflammatory mediators seem to affect disease activity.

S everal autoimmune, rheumatic diseases modulate disease activity during and after pregnancy. Rheumatoid arthritis (RA) improves in the majority of patients, whereas ankylosing spondylitis (AS) remains active and is mitigated only in late pregnancy. ${ }^{2}$ Aggravation of disease symptoms after delivery is commonly seen in both diseases and occurs, in general, within the first 6 months post partum. Pregnancy induces changes in the maternal immune system in order to protect the fetus from immunological attack by the mother. Research over the past decade has indicated that no general immunosuppression takes place in the maternal system, rather a shift from a prevailing Thl response to a type Th2 response. ${ }^{3}$ CD4+ T cells can be divided into two subsets: one is the $\mathrm{T}$ helper 1 type characterised by production of interferon $\gamma($ IFN $\gamma$ ), interleukin (IL) 12, tumour necrosis factor $\beta$ (TNF $\beta)$, and IL2 and involved in cell mediated immunity. The other T cell subset consists of Th2 committed cells, which mainly produce IL4, IL10, and IL13, thereby enhancing humoral immunity. The immunological changes taking place during and after pregnancy may modulate disease symptoms according to the underlying pathophysiology of the disease in question. In RA, a Thl-type immune response is predominant, whereas a Th0 or Th2 type prevails in $\mathrm{AS}^{4}{ }^{4}$

IFN $\gamma$ is a major contributor to a Thl immune response, up regulating Thl cell differentiation and inhibiting Th2 cell development. ILI $\beta$ and TNF $\alpha$ are proinflammatory cytokines that contribute to synovitis and joint destruction in both RA and AS..$^{5-7}$ IL10 down regulates production of proinflammatory cytokines by Thl cells and macrophages. In pregnancy, IL10 counteracts pregnancy related disorders, such as fetal growth restriction as well as fetal death and pre-eclampsia. ${ }^{3} 8$
The immune modulating activities of cytokines are also regulated by soluble cytokine receptors like TNF receptor (TNFR) which can buffer the biological effects of TNF $\alpha .{ }^{9}$ Another natural inhibitory mechanism involves the blocking of receptor binding by cytokine receptor antagonists like ILIRa. ${ }^{10}$

The CD30 receptor belongs to the TNF/nerve growth factor receptor superfamily. CD30 is normally expressed on a subset of activated $\mathrm{T}$ cells producing Th2-type cytokines. ${ }^{11}$ The soluble form of $\mathrm{CD} 30$ ( $\mathrm{SCD} 30$ ) released upon T cell activation by proteolytic cleavage is regarded as a measure of CD30 turnover. Raised levels of sCD30 have been detected in Th2 dominated diseases like systemic lupus erythematosus, ${ }^{12}$ systemic sclerosis, ${ }^{13}$ ulcerative colitis, ${ }^{14}$ and allergic disorders. ${ }^{15}$

The objective of this study was to investigate changes of circulating cytokines and regulatory molecules with a focus on the Thl/Th2 balance during and after pregnancy in patients and healthy controls. By analysing the type of cytokine pattern we sought to determine if the different clinical responses to pregnancy were related to a particular immune response.

\footnotetext{
Abbreviations: AS, ankylosing spondylitis; BASDAl, Bath Ankylosing Spondylitis Activity Index; CRP, C reactive protein; ELISA, enzyme linked immunosorbent assay; IFN $\gamma$, interferon $\gamma$; IL, interleukin; ILIRa, interleukin 1 receptor antagonist; JIA, juvenile idiopathic arthritis; NSAIDs, non-steroidal anti-inflammatory drugs; PGA, physician's global assessment; RA, rheumatoid arthritis; RADAI, RA Disease Activity Index; sCD30, soluble CD30; sTNFR, soluble tumour necrosis factor receptor; $\mathrm{TNF}$, tumour necrosis factor
} 


\section{PATIENTS AND METHODS Patients and samples}

The longitudinal prospective study was performed at the Department of Rheumatology and Clinical Immunology/ Allergology of the University Hospital of Bern after approval by the institutional review board of Bern. Additional sequential serum samples (collected after centrifugation of venous blood) from 10 pregnant patients with RA and 6 patients with juvenile idiopathic arthritis (JIA), and from 8 healthy pregnant women were provided by Professor JL Nelson, Seattle, USA and by Dr G Hebisch, Department of Gynaecology at the University Hospital of Zürich, respectively.

A total of 34 pregnant patients, 19 with RA, 6 with JIA, 9 with AS (10 pregnancies), and 30 healthy pregnant women matched for age were included in the study. Ten nonpregnant, age matched healthy women were included to get the background measurements for the age group, and 9 nonpregnant patients with RA and 11 patients with AS provided background data of a chronic, inflammatory disease. Patients with RA fulfilled the American College of Rheumatology criteria, ${ }^{16}$ and patients with AS the criteria of the European Spondylarthropathy Study Group (ESSG). ${ }^{17}$ The mean age of pregnant patients was 31 (range 21-38), of pregnant healthy women 33 (21-40), of non-pregnant patients 30 (24-37), and of non-pregnant controls 29 years (range 24-35). At the time of blood sampling, none of the participating women had any known infections or was close to labour.

All pregnant women recruited at the University Hospital of Bern were assessed by clinical examination and measurement of $\mathrm{C}$ reactive protein (CRP) at each trimester of pregnancy: gestational week 9-12, gestational week 20-23, gestational week 32-34, and 6, 12, and 24 weeks post partum. Four patients with RA, four with AS, and three healthy women also had blood sampling 8-12 weeks before the index pregnancy. Clinical evaluation was carried out by the RA Disease Activity Index (RADAI) and the tender and swollen joint count ${ }^{18}$ in patients with RA and by the Bath Ankylosing Spondylitis Activity Index (BASDAI) ${ }^{19}$ in patients with AS. Overall disease activity was measured by the physician's global assessment (PGA, a visual analogue scale from 0 to 100)..$^{20} \mathrm{~A}$ remission of the disease during pregnancy was defined as a PGA score of 0, improvement as a decrease of PGA of 20, and active disease as a PGA score $>20$. In all pregnant patients recruited by Dr JL Nelson, disease activity was expressed in three ways: remitted, improved, or active. The six patients with JIA had polyarticular disease and five were positive for rheumatoid factor. Their serum samples were analysed together with those of patients with RA.

\section{Drug treatment during pregnancy}

At study entry six patients were receiving intramuscular gold or sulfasalazine, seven low dose prednisone, and eight nonsteroidal anti-inflammatory drugs (NSAIDs). At the third trimester, two were receiving sulfasalazine, three prednisone, and five NSAIDs. At the post partum aggravation, 28 patients received one of the mentioned drugs or anti-TNF therapy.

\section{Enzyme linked immunosorbent assay (ELISA)}

Venous blood samples obtained from patients and controls were drawn into tubes containing 3.8\% trisodium citrate as an anticoagulant. Plasma was prepared by centrifugation for 15 minutes and aliquots were stored at $-80 \mathrm{C}$. Samples were thawed and assayed for levels of sTNFR (p75), ILlRa, and sCD30 by solid phase sandwich ELISA. The minimal detectable concentrations for the sTNFR ELISA (R\&D Systems, Minneapolis, USA) and the ILIRa ELISA (R\&D Systems, Minneapolis, USA) were $<1.0 \mathrm{pg} / \mathrm{ml}$ and $14 \mathrm{pg} / \mathrm{ml}$, respectively. The instant ELISA for $\mathrm{sCD} 30$ (Bender MedSystems, Vienna, Austria) had a detection limit of 0.5 $\mathrm{U} / \mathrm{ml}$. ELISA kits were also used to detect levels of IFN $\gamma$ (Biosource International, Europe, Nivelle, Belgium), ILı $\beta$ (R\&D Systems, Minneapolis, USA), and IL10 (Immunotech, Marseille, France) in the plasma. For these last assays the detection limits were as follows: $<4 \mathrm{pg} / \mathrm{ml},<\mathrm{pg} / \mathrm{ml}$, and $5 \mathrm{pg} / \mathrm{ml}$. Intra-assay precision and interassay precision of all ELISAs applied were $<10 \%$. All cytokine assays were performed according to the manufacturer's instructions.

\section{Statistics}

Data were analysed using the SPSS 11.0 software package. The associations between clinical measurements of disease activity and the TNFR, ILIRa, and SCD30, respectively, were analysed using Spearman's rank correlation. Correlation was considered strong if the correlation coefficient was $\geqslant 0.70$, moderate to substantial between 0.30 and 0.70 , and weak if $\leqslant 0.30$. We applied the Mann-Whitney U test to compare the median levels of the cytokines measured in pregnant subjects with those of the non-pregnant controls. To analyse the longitudinal change of cytokines we used the Wilcoxon test for paired data. Graphical presentation of the summary scores are given in box plots displaying the median and 25th75 th centiles and the range of values. Values of $p<0.05$ were considered significant.
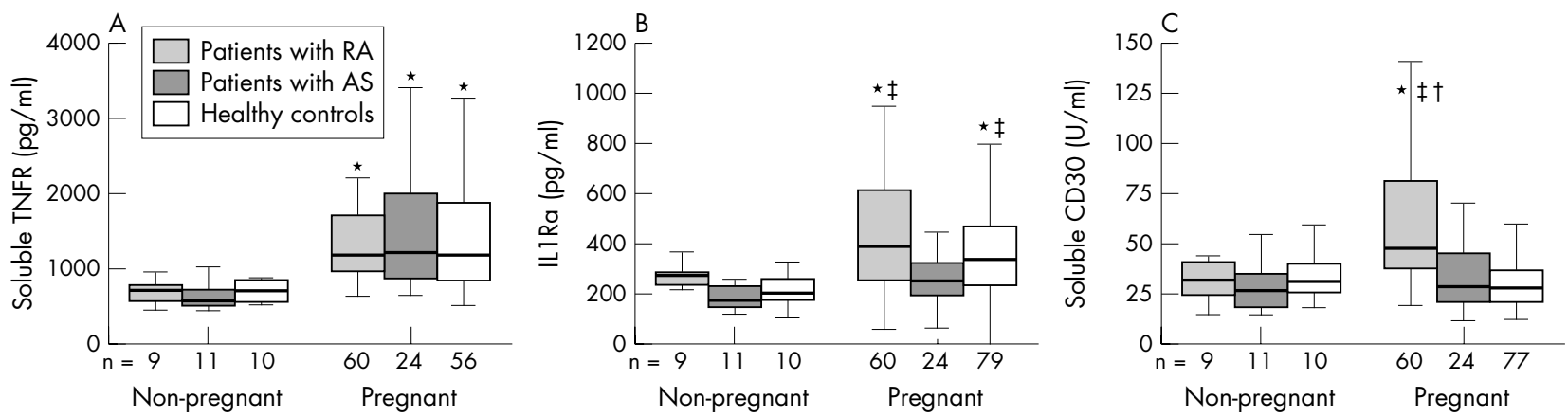

Figure 1 Levels of (A) sTNFR, (B) ILIRa, and (C) sCD30 in patients with RA, patients with AS, and healthy women. Values presented in the group of non-pregnant (no pre-pregnancy or postpartum data included) and pregnant (pooled data of first, second, and third trimester) subjects. Horizontal bar within the box marks the median, the boxes represent the range of $\pm 25 \%$ around the median (interquartile range). Vertical bars indicate $95 \%$ confidence interval. *Significant difference compared with the non-pregnant control group ( $p<0.05$ by Mann-Whitney $U$ test); $†$ significant difference compared with healthy pregnant women ( $p<0.05$ by Mann-Whitney $U$ test); $\ddagger$ significant difference compared with pregnant patients with AS ( $p<0.05$ by Mann-Whitney U test). 


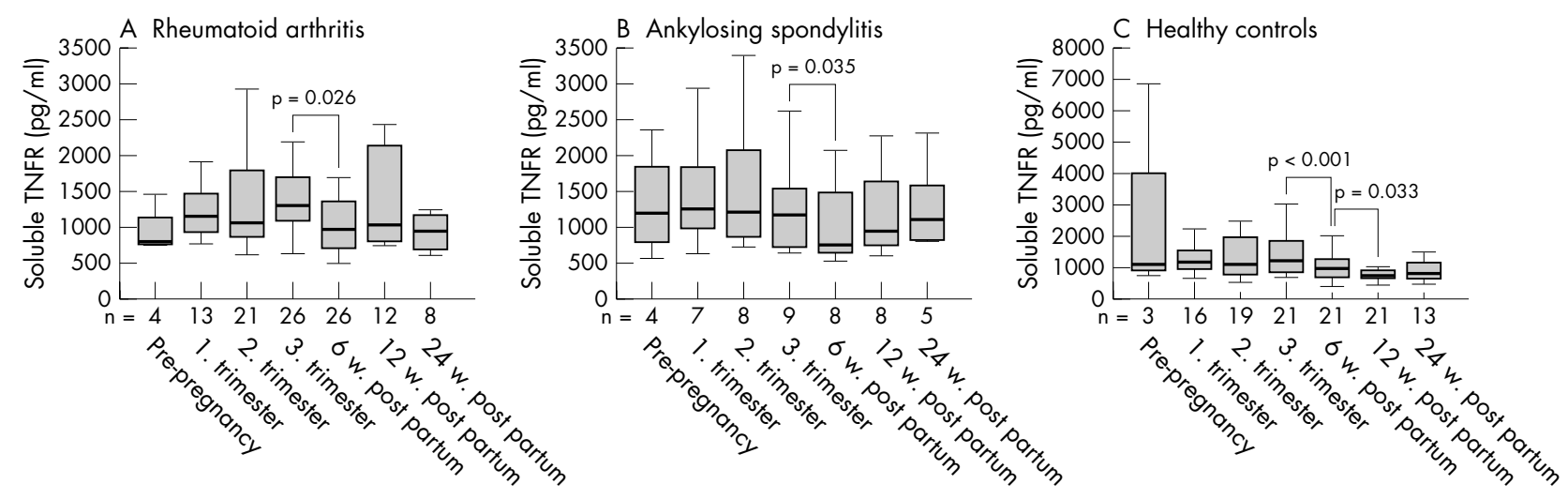

Figure 2 Levels of sTNFR before, during (first, second, and third trimester), and after pregnancy (6, 12, and 24 weeks post partum) in patients with (A) RA or (B) AS, and (C) in healthy controls. Horizontal bar within the box marks the median, the boxes represent a range of $\pm 25 \%$ around the median (interquartile range). Vertical bars indicate $95 \%$ confidence interval. Significant changes indicated by p values (Wilcoxon test for paired data).

\section{RESULTS}

Patients' characteristics and clinical outcome during pregnancy

All patients and healthy women had uncomplicated pregnancies with delivery of healthy children between 36 and 40 weeks of gestation. During pregnancy, 17 patients with RA and five with JIA improved, but the disease remained active in the remaining three patients. Except for two patients with AS with minimal disease activity at study entry, a varying disease course with active disease in the first and second trimester was observed in eight pregnancies. Four patients with AS improved in the third trimester. Aggravation of disease symptoms occurred in 22 patients with RA/JIA and in eight patients with AS between 6 and 12 weeks after delivery.

\section{Cytokines and cytokine receptors}

Low levels of IL10 were sporadically found in five samples, whereas IFN $\gamma$ and ILI $\beta$ were below detection levels in the samples tested. The sTNFR values of two patients with RA measured in the postpartum period were excluded because they had started anti-TNF treatment.

\section{Circulating levels of sTNFR, ILIRa, and SCD30 in pregnant women compared with non-pregnant women}

Significantly higher circulating levels of sTNFR (fig lA; RA: $\mathrm{p}<0.001$, AS $\mathrm{p}<0.001$, healthy: $\mathrm{p}=0.001$ ) were measured in the cohorts of pregnant women compared with non-pregnant women matched for age. Levels of ILIRa were significantly raised in pregnant healthy women and pregnant patients with RA compared with non-pregnant controls (fig 1B; healthy: $p=0.001$, RA: $p=0.034$ ), and they exceeded levels measured in pregnant patients with AS (RA: $p=0.002$; healthy: $p=0.013)$. Only patients with RA showed significantly higher levels of sCD30 (fig lC) in pregnant compared with non-pregnant subjects $(\mathrm{p}=0.001)$, and compared with pregnancy levels of patients with AS $(\mathrm{p}<0.001)$ and healthy women $(p<0.001)$. Among the groups of non-pregnant women, no significant differences were seen for sTNFR, IL1Ra, and SCD30.

\section{Changes of sTNFR-75, IL $1 R a$, and sCD30 during and after pregnancy}

A gradual, albeit not significant, increase of sTNFR occurred both in healthy women and patients during pregnancy, followed by a significant decrease of sTNFR post partum (figs $2 \mathrm{~A}, \mathrm{~B}, \mathrm{C})$. A moderate negative correlation $\left(r_{\mathrm{s}}=-0.448\right.$, $\mathrm{p}=0.05)$ was observed between sTNFR and RADAI. None of the other clinical assessments correlated with levels of STNFR.

In patients with RA and AS, a significant rise of ILIRa appeared from the second to the third trimester of pregnancy (figs $3 \mathrm{~A}$ and $\mathrm{B}$ ). In parallel, disease activity as measured by the PGA was at its lowest in the second and third trimester. In healthy women no significant increase of IL1Ra was found
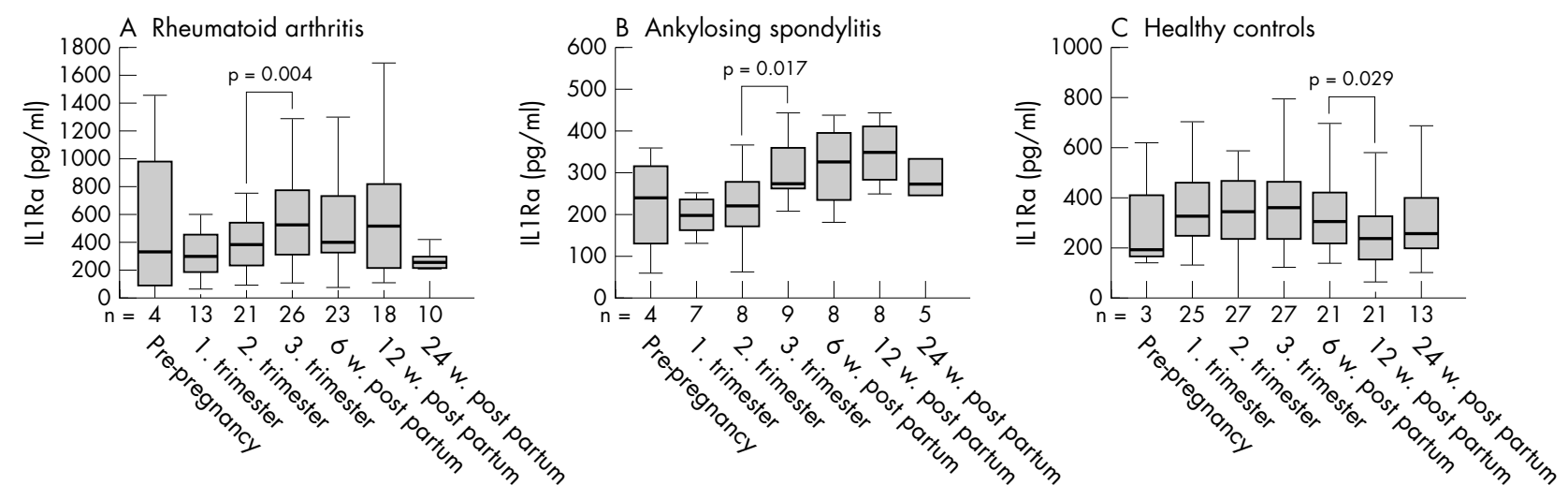

Figure 3 Levels of ILIRa before, during (first, second, and third trimester), and after pregnancy (6, 12, and 24 weeks post partum) in patients with (A) RA or (B) AS, and (C) in healthy controls. Horizontal bar within the box marks the median, the boxes represent a range of $\pm 25 \%$ around the median (interquartile range). Vertical bars indicate $95 \%$ confidence interval. Significant changes indicated by $\mathrm{p}$ values (Wilcoxon test for paired data). 


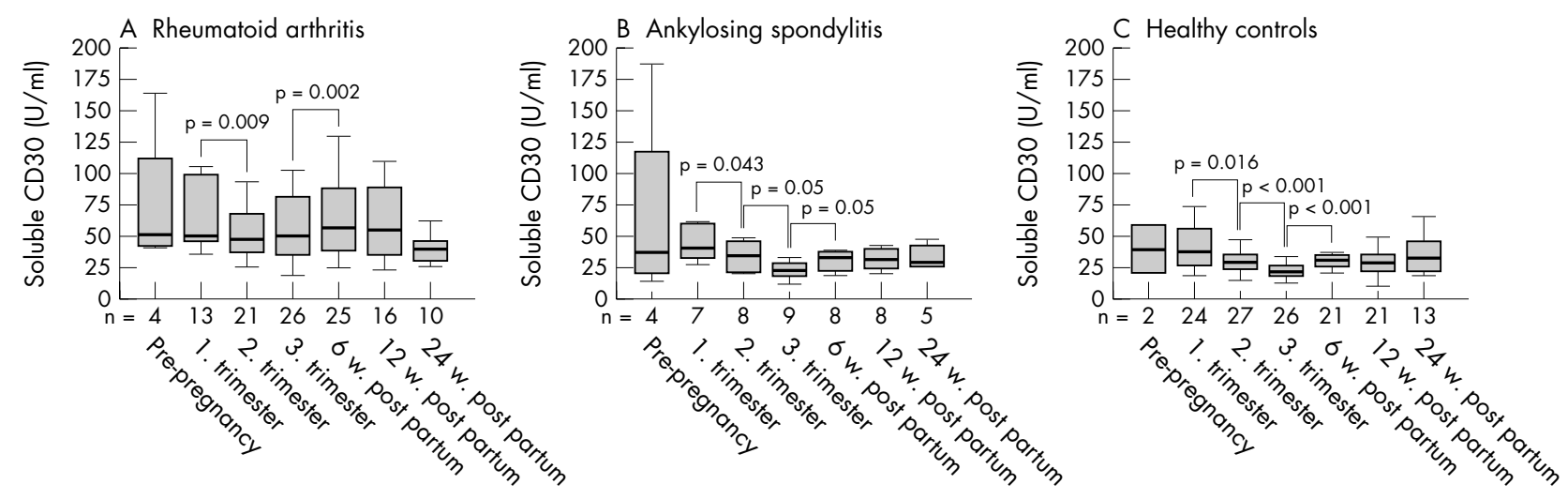

Figure 4 Levels of $s \mathrm{CD} 30$ before, during (first, second, and third trimester), and after pregnancy (6, 12, and 24 weeks post partum) in patients with (A) RA or (B) AS, and (C) in healthy controls. Horizontal bar within the box marks the median, the boxes represent a range of $\pm 25 \%$ around the median (interquartile range). Vertical bars indicate $95 \%$ confidence interval. Significant changes indicated by p values (Wilcoxon test for paired data).

during pregnancy, but a significant decrease of ILIRa occurred from 6 to 12 weeks post partum (fig 3C). Levels of ILIRa in patients with RA and AS correlated weakly to moderately with disease activity measured by the PGA $\left(r_{\mathrm{s}}=-0.269, \mathrm{p}=0.01\right)$, the tender joint count $\left(r_{\mathrm{s}}=-0.349\right.$, $\mathrm{p}=0.01)$, and the swollen joint count $\left(r_{\mathrm{s}}=-0.263, \mathrm{p}=0.01\right)$, but not with the RADAI or BASDAI.

sCD30 decreased gradually during pregnancy and showed an increase at 6 weeks post partum in the three groups of pregnant women (figs $4 \mathrm{~A}, \mathrm{~B}$, and C). In patients with RA and AS, levels of sCD30 did not correlate with any of the clinical assessment instruments.

\section{DISCUSSION}

Our longitudinal study comparing pregnant patients with rheumatic disease and healthy pregnant women found similar cytokine profiles in both groups, with few quantitative differences. This can be expected in patients who enter pregnancy in a state of low disease activity and with little or no organ involvement as did our patients. Thus the physiological alterations induced by pregnancy are not profoundly affected by a chronic inflammatory state, but provide a cytokine milieu that supports pregnancy. In agreement with other studies comparing healthy pregnant women with non-pregnant controls, ${ }^{21}{ }^{22}$ we found raised levels of ILIRa and STNFR in pregnant patients and controls, whereas IL1 $\beta$, IFN $\gamma$, and IL10 were undetectable. Results are conflicting for the circulating levels of IFN $\gamma$ and ILI $\beta$, which have been found either absent or in low levels during pregnancy. ${ }^{23-25}$ The inability to detect circulating IL10 in pregnancy corresponds with another longitudinal study investigating IL10 in plasma of healthy pregnant women at each trimester. ${ }^{22}$ By contrast, low levels of IL10 were found in a cross sectional study of women in their second and third trimester. ${ }^{26}$

Inflammatory rheumatic diseases are associated with a proinflammatory cytokine profile systemically and locally not only at times of active symptoms but also during quiescent disease. $^{892728}$ Up regulation of the inflammatory cytokine IL1 $\beta$ has been reported in RA and AS, sometimes accompanied by an ILlRa deficiency. ${ }^{29-31}$ Treatment with the recombinant TNFR:Fc fusion protein and with recombinant ILIRa is efficacious in RA and AS. ${ }^{32-35}$ Thus, increased levels of ILIRa in the third trimester might overcome a deficiency in pregnant patients with RA and AS and lead to improvement of the disease. The negative correlation between ILIRa and disease activity supports this notion. Likewise, raised sTNFR levels in pregnant patients with RA and AS might contribute to an improvement of the disease in late pregnancy.
It has been suggested that the remission so often seen in RA during pregnancy may relate to the increased gestational secretion of IL10, resulting in the induction of tolerance. ${ }^{36}$ In our study IL10 was either below detection levels or present in few patients with active RA post partum. Even in the absence of raised circulating levels of IL10, T cells of peripheral blood could still increase their IL10 secretion as shown recently in four pregnant patients with RA. ${ }^{37}$ However, the role of ILl0 in joint inflammation is ambiguous. Experiments on joint tissues have shown that inflammation is suppressed by IL10. ${ }^{38}$ Furthermore, Th2 committed T cells and regulatory $\mathrm{T}$ cells, which counteract inflammation and autoimmunity, produce high levels of IL10. ${ }^{14}{ }^{39}$ On the other hand, a study of IL10 polymorphism in RA found an association between high production of ILl0 and joint destruction..$^{40}$ This may, in part, be due to the effect of IL10 on monocyte maturation, rendering them into tissue infiltrating cells, ${ }^{41}$ or to the stimulation of autoantibody production and enhancement of FC gamma receptor expression on monocytes. ${ }^{42}$ Also in patients with active spondyloarthropathy raised levels of circulating IL10 have been found. ${ }^{29}$

SCD30 is an indirect marker for a Th2 immune response and can be induced by progesterone together with IL4 production. $^{43}$ A rise of $\mathrm{sCD} 30$ during pregnancy would therefore be expected. Interestingly, this was observed exclusively in our pregnant patients with RA, who had markedly higher gestational levels of sCD30 than the other groups of pregnant women and than non-pregnant patient cohorts. Owing to the few pre-pregnancy samples available, no statement can be made about whether sCD30 levels increased during the first trimester in patients with RA and then decreased again. A counterregulatory role for CD30+ T cells, providing an attempt to control inflammation in a Thl driven disease like RA, has been discussed, ${ }^{44}$ and higher circulating levels of sCD30 have been found in non-pregnant patients with RA than in healthy controls. ${ }^{45}$ The latter finding was not confirmed by our results. In our longitudinal study, concentrations of sCD30 in patients and healthy controls decreased progressively during pregnancy, possibly as a result of the increasing plasma volume. The same dynamics were previously shown by others investigating $\mathrm{SCD} 30$ in healthy pregnant women. ${ }^{46}$ However, when the ratio of sCD26, a Thl related molecule, and sCD30 was analysed, a predominance of the Th2 marker was demonstrated throughout pregnancy. Circulating sCD30 levels in our cohort of pregnant patients with RA did not correlate with disease activity measurements. This is at variance with another study showing an inverse correlation between $\mathrm{sCD} 30$ and CRP. ${ }^{47}$ Lack of correlation in our study was probably due to the low range 
of disease activity, with mostly normal CRP levels among our patients with RA.

Our study has several limitations-for example, the limited number of patients included and the small number of women with pre-pregnancy measurements. The gestational rise of a marker is sometimes only reflected by a significant drop after delivery and the significant difference of circulating levels in pregnant and non-pregnant subjects. Taking into account the dilution effect of the increasing plasma volume during pregnancy, emphasises that indeed an increase of the measured protein has taken place. A cytokine increase might also be hidden in the large interindividual variation that arises from different levels of disease activity at study entry, from treatment, and from genetic variation. However, the limited number of patients does not allow a separate analysis for subgroups.

To summarise, among the cytokines and regulatory molecules for which tests were carried out, an increase of the anti-inflammatory cytokines ILIRa and sTNFR was found during pregnancy. IFN $\gamma$ and IL10, markers of a Th1 and Th2 response, respectively, were either low or undetectable. The possibility cannot be excluded that at a local level a more pronounced change in the Thl/Th2 balance during and after pregnancy might have been measured. In addition, up regulation of ILIRa and STNFR as well as SCD30 in patients with RA during pregnancy may be indirect signs of a Th2 immune response because Th2 cytokines have been shown to induce the production of both STNFR and ILl Ra. ${ }^{48}{ }^{49}$ On the other hand, evidence accumulates that pregnancy promotes not only a Th2 response, but rather an immunomodulation that is complex and dependent on the stage of pregnancy. ${ }^{50}$ Because most of the disease activity markers did not correlate with the changes of circulating cytokines, the extent to which they contribute to pregnancy related improvement of disease activity in the third trimester remains open.

\section{ACKNOWLEDGEMENTS}

The study was supported by grant 31-59979 from the Swiss National Research Fund, and by grants from the Kurt and Senta HermannStiftung and from the Swiss League against Rheumatism.

\section{Authors' affiliations}

M Østensen, F Förger, P M Villiger, Department of Rheumatology and Clinical Immunology and Allergology, University Hospital, Bern,

Switzerland

J L Nelson, Fred Hutchinson Cancer Research Center, and the Division of Rheumatology, University of Washington, Seattle, Washington, USA

A Schuhmacher, County Hospital of Belp, Switzerland

G Hebisch, Department of Gynaecology at the University Hospital of Zürich, Switzerland

\section{REFERENCES}

1 Østensen M, Husby G. A prospective clinical study of the effect of pregnancy on rheumatoid arthritis and ankylosing spondylitis. Arthritis Rheum 1983;26:1155-9.

2 Gran JT, Østensen M. Spondylarthritides in females. Ballieres Clin Rheumatol 1998;12:695-715.

3 Wegmann TG, Lin H, Guilbert L, Mosmann TR. Bidirectional cytokine interactions in the maternal-fetal relationship: is successful pregnancy a Th2 phenomenon? Immunology Today 1993;14:353-6.

4 van Roon JAG, Biilsma JWJ. Th2 mediated regulation in RA and the spondylarthropathies. Ann Rheum Dis 2002;61:951-4.

5 Williams RO, Feldmann M, Maini RN. Cartilage destruction and bone erosion in arthritis: the role of tumor necrosis factor alpha. Ann Rheum Dis 2000;59(suppl I):i75-80.

6 Arend WP, Dayer J-M. Inhibition of the production and effects of interleukin-1 and tumor necrosis factor $\alpha$ in rheumatoid arthritis. Arthritis Rheum 1995; 38:151-60.

7 Braun J, Bollow M, Neure L, Seipelt E, Seyrekbasan F, Herbst H, et al. Use of immunohistologic and in situ hybridization techniques in the examination of sacroiliac joint biopsy specimens from patients with ankylosing spondylitis. Arthritis Rheum 1995;38:499-505.
8 Chaouat G, Menu E, Clark DA, Dy M, Minkowski M, Wegmann TG. Control of fetal survival in CBA $\times$ DBA/2 mice by lymphokine therapy. J Reprod Fertil 1990;89:447-58.

9 Smith CA, Davis T, Anderson D, Solam L, Veckmann MP, Jerzy R, et al. A receptor for tumor necrosis factor defines an unusual family of cellular and viral proteins. Science 1990;248:1019-23.

10 Arend W, Gabay C. Physiologic role of interleukin-1 receptor antagonist. Arthritis Res 2000;2:245-8.

11 Del Prete GF, De Carli M, Almerigogna F, Daniel CK, D'Elios M, Zancuoghi F, et al. Preferential expression of CD30 by human CD4+ T cells producing Th2cytokines. FASEB J 1995;9:81-6.

12 Caligaris-Cappio F, Bertero MT, Converso M, Stacchini A, Vinante F, Romagnani S, et al. Circulating levels of soluble CD30, a marker of cells producing Th2-type cytokines, are increased in patients with systemic lupus erythematosus and correlate with disease activity. Clin Exp Rheumatol 1995; 13:339-43

13 Giacomelli R, Cipriani P, Lattanzio R, Di Franco M, Locanto M, Parzanese I, et al. Circulating levels of soluble CD30 are increased in patients with systemic sclerosis (SSc) and correlate with serological and clinical features of the disease. Clin Exp Immunol 1997; 108:42-6.

14 Giacomelli R, Passacantando A, Parzanese I, Vernia P, Klidara N, Cucinelli F, et al. Serum levels of soluble CD30 are increased in ulcerative colitis but not in Crohn's disease. Clin Exp Immunol 1998;111:532-5.

15 Spinozzi F, Agea E, Bistoni O, Forenzy N, Monaco A, Falini B, et al. Local expansion of allergen-specific CD30+ Th2-type gamma delta $T$ cells in bronchial asthma. Mol Med 1995; 1:821-6.

16 Arnett FC, Edworthy SM, Bloch DA, McShane DJ, Fries JF, Cooper NS, et al. The American Rheumatism Association 1987 revised criteria for the classification of rheumatoid arthritis. Arthritis Rheum 1988;31:315-24.

17 Dougados M, van der Linden S, Juhlin R, Huiffeldt B, Amor B, Calin A, et al. The European Spondylarthropathy Study Group: preliminary criteria for the classification of spondylarthropathy. Arthritis Rheum 1991;34:1218-27.

18 Stucki G, Liang MH, Stucki S, Bruhlmann P, Michel BA. A self-administered rheumatoid arthritis disease activity index (RADAl) for epidemiological research. Arthritis Rheum 1995;38:795-8.

19 Garrett S, Jenkinson T, Kennedy LG, Whitelock H, Gaisford P, Calin A. A new approach to defining disease status in ankylosing spondylitis: the Bath Ankylosing Spondylitis Disease Activity Index. J Rheumatol 1994;21:2286-91.

20 Felson DT, Anderson JJ, Boers M, Bombardier C, Chernoff M, Fried B et al. The American College of Rheumatology preliminary core set of disease activity measures for rheumatoid arthritis clinical trials. Arthritis Rheum 1993;36:729-40

21 Kupferminc MJ, Peaceman AM, Aderka D, Wallach D, Peyser RM, Lessing JB, et al. Soluble tumor necrosis factor receptors in maternal plasma and secondtrimester amniotic fluid. Am J Obstet Gynecol 1995;173:900-5.

22 Opsjon SL, Wathen NC, Tingulstad S, Wiedswang G, Sundan A, Waage A, et al. Tumor necrosis factor, interleukin 1, and interleukin-6 in normal human pregnancy. Am J Obstet Gynecol 1993; 169:397-404.

23 Makhseed M, Raghupathy R, Azizieh F, Farhat R, Hassan N, Bandar A. Circulating cytokines and CD30 in normal human pregnancy and recurrent spontaneous abortions. Hum Reprod 2000;15:2011-17.

24 Bahar AM, Ghalib HW, Moosa RA, Zaki MSZ, Thomas C, Nabri OA. Maternal serum interleukin-6, interleukin-8, tumor necrosis factor- $\alpha$ and interferon- $\gamma$ in preterm labor. Acta Obstet Gynecol Scand 2003:82:543-9.

25 Hebisch G, Neumaier-Wagner PM, Huch R, von Mandach U. Maternal serum interleukin- 1 beta, $-6 \&-8$ levels and potential determinants in pregnancy and peripartum. J Perinat Med 2004;32:475-80

26 Ellis J, Wennerholm UB, Bengtsson A, Lilia H, Petterson A, Sultan B, et al. Levels of dimethylarginines and cytokines in mild and severe preeclampsia. Acta Obstet Gynecol Scand 2001;80:602-8.

27 Keller C, Webb A, Davis J. Cytokines in the seronegative spondylarthropathies and their modification by TNF blockade: a brief report and literature review. Ann Rheum Dis 2003:62:1128-32.

28 Wais T, Fierz W, Stoll T, Villiger PM. Subclinical disease activity in systemic lupus erythematosus: immunoinflammatory markers do not normalize in clinical remission. J Rheumatol 2003;30:2133-9.

29 Kay J, Calabrese L. The role of interleukin- 1 in the pathogenesis of rheumatoid arthritis. Rheumatology (Oxford) 2004;43(suppl 3):III2-9.

30 Vazquez-Del MM, Garcia-Gonzalez A, Munoz-Valle JF, Garcia-Iglesias T, Martinez-Bonilla G, Bernard-Medina G, et al. Interleukin 1 beta (IL-1 beta), IL10 , tumor necrosis factor-alpha, and cellular proliferation index in peripheral blood mononuclear cells in patients with ankylosing spondylitis. J Rheumatol 2002;29:522-6.

31 Firestein GS, Boyle DL, Yu C, Paine MM, Whisenand TD, Zvaifler NJ, et al. Synovial interleukin-1 receptor antagonist and interleukin-1 balance in rheumatoid arthritis. Arthritis Rheum 1994;37:644-52.

32 Jiang Y, Genant HK, Watt I, Cobby M, Bresnihan B, Aitchison R, et al. A mulicenter, double-blind, randomized, placebo-controlled study of recombinant human interleukin-1 receptor antagonist in patients with rheumatoid arthritis. Radiologic progression and correlation of Genant and Larson score. Arthritis Rheum 2000;43:1001-9.

33 Tan AL, Marzo-Ortega H, O'Connor P, Fraser A, Emery P, McGonagle D. Efficacy of anakinra in active ankylosing spondylitis: a clinical and magnetic resonancy imaging study. Ann Rheum Dis 2004;63:1041-5 doi, 10.1136/ ard.2004.02800 [published Online First 5 April 2004]

34 Moreland LW, Schiff MH, Baumgartner SW, Tindall EA, Fleischmann RM, Bulpitt KJ, et al. Etanercept therapy in rheumatoid arthritis. A randomized, controlled trial. Ann Intern Med 1999;130:478-86

35 Gorman JD, Sack KE, Davis JC Jr. Treatment of ankylosing spondylitis by inhibition of tumor necrosis factor $\alpha$. N Engl J Med 2002;346:1349-56. 
36 Huizinga TWJ, van der Linden MW, Deneys-Laporte V, Breedveld FC. Interleukin-10 as an explanation for pregnancy-induced flare in systemic lupus erythematosus and remission in rheumatoid arthritis. Rheumatology (Oxford) 1999:38:496-8.

37 Munoz-Valle JF, Vazquez-Del Mercado M, Garcia-lglesias T, OrozcoBarocio G, Bernard-Medina G, Martinez-Bonilla $G$, et al. $T(H) 1 / T(H) 2$ cytokine profile, metalloprotease-9 activity and hormonal status in pregnant rheumatoid arthritis and systemic lupus erythematosus patients. Clin Exp Immunol 2003;13:377-84.

38 Mulherin D, FitzGerald O, Breshnihan B. Synovial tissue macrophage populations and articular damage in rheumatoid arthritis. Arthritis Rheum 1996;39:1 15-24.

39 Annunziato F, Cosmi L, Liotta F, Lazzeri E, Manetto R, Vanini V, et al. Phenotype, localization, and mechanism of suppression of CD4+CD25+ human thymocytes. J Exp Med 2002;196:379-87.

40 Lard LR, van Gaalen FA, Schonkeren JJ, Pieterman EJ, Stoeken G, Vos K, et al. Association of the -2849 interleukin-10 promoter polymorphism with autoantibody production and joint destruction in rheumatoid arthritis. Arthritis Rheum 2003:48:1841-8.

41 Kawanaka N, Yamamura M, Aita T, Morita Y, Okamoto A, Kawashima M, et al. CD14+,CD16+ blood monocytes and joint inflammation in rheumatoid arthritis. Arthritis Rheum 2002;46:2578-86.

42 van Roon J, Wiingaarden S, Lafeber FP, Damen C, van de Winkel J $\mathrm{Bijlsma} \mathrm{JW}$. Interleukin 10 treatment of patients with rheumatoid arthritis enhances Fc gamma receptor expression on monocytes and responsiveness to immune complex stimulation. J Rheumatol 2003;30:648-51.
43 Piccini MP, Giudizi MG, Biagiotti R, Beloni L, Giannarini L, Sampognaro S, et al. Progesterone favors the development of human T helper cells producing Th2-type cytokines and promotes both IL- 4 production and membrane CD30 expression in established Th1 cell clones. J Immunol 1995;155:128-33.

44 Gerli R, Lunardi C, Vinante F, Bistoni O, Pizzolo G, Pitzalis C. Role of CD30+ $\mathrm{T}$ cells in rheumatoid arthritis: a counter-regulatory paradigm for Th1-driven diseases. Trends Immunol $2001 ; 2: 72-7$.

45 Okamoto A, Yamamura M, Iwahashi M, Aita T, Ueno A, Kawashima M, et al. Pathophysiological functions of CD30+CD4+ T cells in rheumatoid arthritis. Acta Med Odayama 2003;57:267-77.

46 Hoshimoto KI, Ohta N, Ohkura T, Inaba N. Changes in plasma soluble CD26 and CD30 during pregnancy: markers of Th1/Th2 balance? Gynecol Obstet Invest 2000:50:260-3.

47 Gerli R, Bistoni O, Lunardi C, Giacomelli R, Tomassini C, Giagini P, et al. Soluble CD30 in early rheumatoid arthritis as a predictor of good response to second-line therapy. Rheumatology (Oxford) 1999;38:1282-4.

48 Vannier E, Miller LC, Dinarello CA. Coordinated antiinflammatory effects of interleukin-4: inerleukin 4 suppresses interleukin 1 production but up-regulates gene expression and synthesis of interleukin 1 receptor antagonist. Proc Natl Acad Sci USA 1992;89:4076-80.

49 Joyce DA, Steer JH. IL-4, IL-10 and IFN- $\gamma$ have distinct, but interacting, effects of differentiation-induced changes in TNF- $\alpha$ and receptor release by cultured human monocytes. Cytokine 1996;8:49-57.

50 Chaouat G, Ledée-Bataille N, Dubanchet S, Zourbas S, Sandra O, Martal J. Th1/Th2 paradigm in pregnancy: Paradigm lost? Int Arch Allergy Immunol 2004;139:93-119. 